ANSP-M-3

APRIL 1972

Copy No. 21

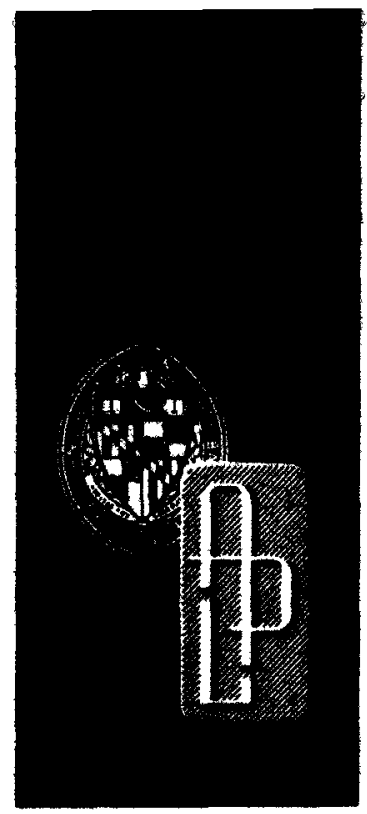

Aerospace Nuclear Safety Program

\title{
PIONEER F/SNAP 19 HEAT SOURCE THERMAL ANALYSIS
} by D. W. CONN and R. K. FRAZER

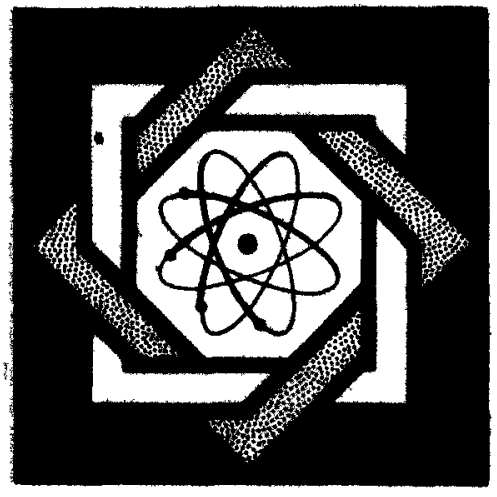

THE JOHNS HOPKINS UNIVERSITY • APPLIED PHYSICS LABORATORY 


\section{DISCLAIMER}

This report was prepared as an account of work sponsored by an agency of the United States Government. Neither the United States Government nor any agency Thereof, nor any of their employees, makes any warranty, express or implied, or assumes any legal liability or responsibility for the accuracy, completeness, or usefulness of any information, apparatus, product, or process disclosed, or represents that its use would not infringe privately owned rights. Reference herein to any specific commercial product, process, or service by trade name, trademark, manufacturer, or otherwise does not necessarily constitute or imply its endorsement, recommendation, or favoring by the United States Government or any agency thereof. The views and opinions of authors expressed herein do not necessarily state or reflect those of the United States Government or any agency thereof. 


\section{DISCLAIMER}

Portions of this document may be illegible in electronic image products. Images are produced from the best available original document. 
ANSP-M-3

APRIL 1972

\section{Aerospace Nuclear Safety Program}

\section{PIONEER F/SNAP 19 HEAT SOURCE THERMAL ANALYSIS}

by D. W. CONN and R. K. FRAZER

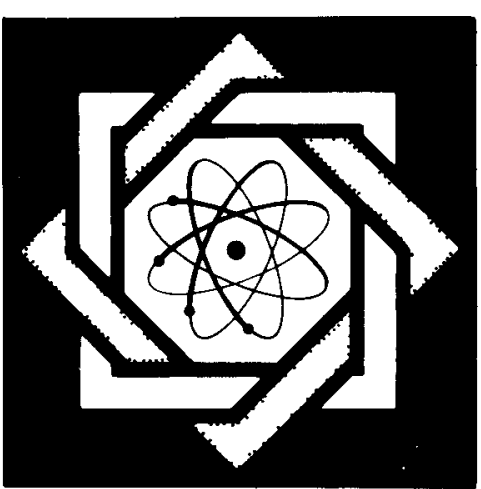

THE JOHNS HOPKINS UNIVERSITY • APPLIED PHYSICS LABORATORY

8621 Georgia Avenue 。Silver Spring, Maryland ○ 20910
This repurt was prepared as an account of work sponsored by the United States Government. Neither the United States nor the United States Atomic Energy

Commission, nor any of their employees, nor any of

Com contractors, subcontractors, or ther employees,

ther contractors, subsumes any

lege

pleteness or usefulness of any information, apparatus,

product or process disclosed, or represents that its use

would not infringe privately owned rights. 


\section{FOREWORD}

The work reported herein was conducted by the Applied

Physics Laboratory Aeronautics Division for the Atomic Energy

Commission, Safety Branch, Space Nuclear Systems Office. Activities

of the Aeronautics Division are under the general supervision of

Dr. William Avery. The Project Engineer for the Aerospace Nuclear

Safety Program is James C. Hagan. 


\author{
ABSTRACT \\ As part of the nuclear safety analysis for the Pioneer \\ F/SNAP 19 power system, a two-dimensional thermal analysis of \\ the SNAP 19 heat source was conducted for several mission abort \\ reentries. This report presents the results of the analysis and \\ compares the heat source's critical thermal parameters with the \\ predictions resulting from Teledyne Isotopes' nuclear safety \\ studies. Discussion is also included on (a) the special con- \\ siderations given the orbital decay thermal analysis and (b) \\ the cost/accuracy optimization trade-off conducted for the \\ modelling of the graphite heat shield.
}


A two-dimensional thermal analysis of the Pioneer F/SNAP 19 heat source was conducted to provide confirmation of Teledyne Isotopes' reentry temperature predictions resulting from their nuclear safety analysis. This analysis considered the condition of a flat leading, side-on-stable heat source reentry at 400,000 ft. which yields maximum thermal response for the assembly. Mass and energy transfer effects due to heat shield ablation were considered in the analysis. The analysis examined two superorbital reentries with initial conditions of $\gamma=-8^{\circ}, V=40,000$ fps and $\gamma=-6^{\circ}, V=37,000$ fps in addition to a random orbital decay.

The results of the analysis are summarized by the comparison of the critical thermal parameters, the oxidation-resistant clad member peak temperature and strength member impact temperature, in Table 2. APL's temperature predictions are consistently higher than the Teledyne values for both maximum flight and impact conditions. However, the differences are not great enough to seriously question Teledyne's results. APL's limited temperature results indicate the failure space for clad melting is slightly enlarged from the multiple skip reentry region indicated by Teledyne and should include $V-\gamma$ space in near proximity of the skip boundary. This space suggests a low occurrence probability due to mission abort and should not significantly alter fuel release probabilities reported by Teledyne. Differences in temperature predictions are felt to be due principally to differences 
THE JOHNS MOPKINS UNIVERSITY APPLIED PHYSICS LABORATORY

SILVER SPRING MARYLAND

in heat shield modelling and Teledyne's omission of subsonic oxidation effects.

APL's heat shield thermal model was the result of an optimization study which is also reported in the body of this memo. 
THE JOHNS HOPKINS UNIVERSITY APPLIED PHYSICS LABORATORY

Silver SPRing makrLand

TABLE OF CONTENTS

I. INTRODUCTION

II. PIONEER F/SNAP 19 HEAT SOURCE DESIGN

III. HEAT SOURCE THERMAL MODEL

IV. OPTIMIZATION OF HEAT SHIELD MODEL

V. ORBITAL DECAY CONSIDERATIONS

VI. DISCUSSION OF RESULTS

VII. THERMAL MODEL REFINEMENTS

VIII. CONCLUSIONS

REFERENCES

TABLES

FIGURES 
THE JOHNS HOPKINS UNIVERSITY

APPLIED PHYSICS LABORATORY

SILVER SPRING. MARYLAND

\section{LIST OF TABLES}

Table 1

Effects of Variations in Heat Shield Modelling on Predicted Fuel Capsule Clad Member Temperatures and Computational Costs.

Table 2

Comparison of Two-Dimensional Thermal Results for the Pioneer F/SNAP 19 Heat Source. 


\section{LIST OF FIGURES}

Pioneer F/SNAP 19 Heat Source Design

The SNAP 19 Pioneer F Radiosotope Thermoelectric Generator with T-111 Fuel Capsule

Pioneer F/SNAP 19 Heat Source Two-Dimensional Thermal Model

Pioneer F/SNAP 19 Heat Source Dimensions and Gap Distributions

Heat Shield Thermal Model Variations, Pioneer F/SNAP 19 Heat

Source

Comparison of Clad Member Temperature Profiles Due to Transient and Steady State Heating Rate Considerations for An Orbital Decay Reentry

Temperature Histories for Pioneer F/SNAP 19 Heat Source For Orbital Decay Reentry

Temperature Histories for Pioneer F/SNAP 19 Heat Source For $\gamma_{i}=-8^{\circ}, V_{i}=40,000$ FPS Reentry

Temperature Histories for Pioneer F/SNAP 19 Heat Source for $Y_{i}=-6^{\circ}, V_{i}=37,000$ FPS Reentry APL Estimation of Incremental V- $\gamma$ Space for Clad Melt Failure

11 Comparison of T-I and APL Heat Shield Thermal Models, Pioneer F/SNAP 19 Heat Source 


\section{INTRODUCTION}

A major effort in the review and evaluation of Teledyne's Pioneer $F$ reentry nuclear safety analysis was directed toward a twodimensional thermal analysis of the Pioneer F/SNAP 19 heat source. The primary intent of the analysis was to provide confirmation of Teledyne's predicted thermal response for the critical structural components of the heat source. This effort consisted of two distinct areas of endeavor:

1. Development of a surface energy balance routine for the Standard Heat Transfer Program (1) (SHTP) that considered the energy and associated mass transfer effects related to oxidation and sublimation of graphitic materials, and

2. Development of a thermal model of the Pioneer $F$ heat source and subsequent analysis of the thermal response of the model via the SHTP for pertinent heat source atmospheric entries.

A general surface energy balance routine was developed for the SHTP that permits consideration of any material that experiences surface phase change due to (a) heterogeneous reactions with the boundary layer and/or (b) sublimation. This surface energy balance utilizes the basic features of the CMA ${ }^{(2)}$ and $\mathrm{EST}^{(3)}$ programs developed for the Air Force Rocket Propulsion Laboratory. Development of this surface energy balance technique for specific use in the SHTP is addressed in detail in a separate memo. (4)

The purpose of this memo is to briefly report the results of the two-dimensional thermal analysis of the Pioneer $F$ heat source. 


\section{PIONEER F/SNAP 19 HEAT SOURCE DESIGN}

The basic heat source design is shown in Figure $1 .(5)$ The salient features of the design are as follows:

(a) Heat Shield: A hexagonal external configuration with a minimum wall thickness of 0.28 inches at the flat. The shield is fabricated from POCO AXF-Q1 graphite, a fine-grained artificial graphite, and serves as a sacrificial thermal barrier during entry.

(b) Pyrolytic Graphite Sleeves: Three telescoping sleeves that serve as an insulation barrier to radial heat transfer into the fuel capsule during entry.

(c) Fuel Capsule Clad Member: A Pt/20\% Rh alloy that serves as an oxidation barrier for the strength member in the post impact environment.

(d) Fue1 Capsule Strength Member: A T-111 refractory alloy that serves as the principal load carrying member during flight and at impact.

(e) Fuel Capsule Liner Member: A Ta/low refractory alloy that serves as a chemical barrier between the strength member and fuel. A molybdenum/46\% rhenium foil ( 5 mils thick) surrounding the fuel stack was recently incorporated into the design to further isolate the reactivity of the fuel.

(f) Fue1: A stack of plutonium-molybdenum cermet pucks that generates approximately 645 thermal watts for thermoelectric conversion. 
The heat source is 6.5 inches long, 3.50 inches across the flats and weighs 11.3 pounds in its fueled state. The heat source is packaged into a finned $\mathrm{Mg} / \mathrm{Th}$ alloy housing which contains the thermoelectrics; wherein, the total assembly is designated the SNAP 19 Radioisotopic Thermoelectric Generator (RTG). The complete generator system is shown in Figure 2.(6) There is a total of four RTGs employed on the Pioneer $F$; each $R T G$ is required to generate approximately 30 electrical watts during Jupiter encounter. 


\section{HEAT SOURCE THERMAL MODEL}

The thermal model is shown in Figure 3 and represents a twodimensional section taken at the mid-span of the heat source. The nodal break-up has been chosen to represent a flat leading, side-on trim condition in which stagnation conditions occur at the flat's minimum thickness location (Node 非1). Hypersonic stability data ${ }^{(7)}$ indicate this attitude to be a strong trim condition. It is also the attitude which gives rise to maximum thermal response of the internal structure.

A comparative review ${ }^{(8)}$ of the Pioneer $F$ reentry safety analyses conducted by Sandia and Teledyne indicated preference for the thermal properties (particularly PG c-plane conductivity) and gap distributions used by Teledyne. These data have been incorporated into the APL analysis. The gap sizes are indicated in Figure 4 and represent averaged values for the heated structure for a typical reentry environment. (9) This figure also shows the local outer radius for each of the heat source components. Thermal properties for each of the components can be found in Teledyne's SNAP 19/Pioneer F Safety Analysis Report (SAR). (10) The analysis has assumed that the heat source reenters in its side-on-stable attitude at 400,000 $\mathrm{ft}$. with an initial temperature distribution associated with a nominal operation mode. This is a conservative assumption for a thermal analysis, which implies RTG housing break-up occurs at precisely the time of initial reentry as opposed to the more probable condition of break-up at some point during reentry. Heating rates were based on stagnation values calculated by the Detra, Kemp and Ridde11 correlation ${ }^{(11)}$ or the Sibulkin ${ }^{(12)}$ equation (for $M_{0} \leq 5$ ) for a unit radius sphere and transformed to the heat source configuration by means of the limited experimental heat transfer distribution data acquired at NASA Langley. (13) This procedure was 
previously discussed in APL's comparative review of the Sandia and Teledyne analyses. (8) Shock layer radiation was considered for the appropriate reentries based on the Callis technique (14) (non-gray, nonadiabatic, self-absorbing inviscid radiation model). Surface thermochemistry for the graphite heat shield was based on the Fast Rate oxidation and JANAF (69) equilibrium sublimation mode1s. (15) The thermal model did not consider dimensional changes in the heat shield thermal network due to ablation effects. 
The Standard Heat Transfer Program (SHTP) relies on an explicit numerical solution (forward differencing) for the nodal energy balances; wherein, a minimum computational time step is required to maintain a stable solution. For the Pioneer $F$ thermal model, the minimum time step was predicated on the nodal grid size selected for the graphite heat shield. Specifically, the finer the grid size selected for the heat shield, the smaller the computational time step required for a stable solution and hence, the greater the computer cost for a given reentry analysis. Consequently, optimization of the heat shield became necessary in terms of computational accuracy versus computational cost.

Optimization of the heat shield thermal model was based on an analysis of a $-9^{\circ} / 44 \mathrm{~K}$ fps (flight path angle/velocity) superorbital reentry for a flat leading, side-on-stable attitude with entry initiating at 400,000 ft. This reentry represents a typical initial flight condition in superorbital $V-\gamma$ space for the Pioneer $F$ heat source. The modelling of the heat source's interior structure remained fixed as shown in Figure 3. The parameter of interest for this optimization was the accuracy of the estimate of the fuel capsule's clad member temperature at the forward position (i.e., node 非50, Figure 3) versus computer cost per second of flight time. As previously mentioned, the clad member is a critical design consideration due to its susceptibility to melt failure. Results are summarized in Figure 5 and Table 1. The baseline model (Fig. 5) resulted in exorbitant computer cost and computations using this model were prematurely terminated at 55 seconds due to excessive computer expenditure. The Revision 1 model possessed a larger radial grid on the leeward side, resulting in approximately a 50\% reduction in computer cost rate for 
negligible sacrifice in accuracy. However, this cost rate still remained exorbitant, amounting to about a $\$ 4000.00$ expenditure for an orbital decay analysis. The Revision 2 model resulted in a reduction of the cost rate to a practical leve1. However, the larger radial grid at the windward side resulted in a maximum clad temperature about $50^{\circ} \mathrm{F}$ lower than the maximum temperature (estimated) for the baseline model. The Revision 3 model possessed a tighter circumferential grid at the windward and initial leeward positions to assess circumferential conduction effects on the clad's maximum thermal response. The circumferential effect resulted in a $65^{\circ} \mathrm{F}$ reduction in maximum clad temperature compared to the Revision 2 results. Presumably a tighter circumferential mesh for the baseline model would have produced a similar temperature drop in the clad. The interpretation attached to these results is that the effect of a more coarse radial grid ( 3 nodes, Revision 2) on predicted clad temperatures is approximately the same as a tighter circumferential grid. Consequently, the Revision 2 model provides sufficient computational accuracy to complement its superior cost rating and therefore represents the optimum configuration of the cases under consideration. 


\section{ORBITAL DECAY CONSIDERATIONS}

Although the Revision 2 heat shield mode1 provides a practical computer cost rate, the expenditure for an orbital decay reentry analysis (i.e., a 2100 second flight period from 400,000 ft) was still estimated to exceed $\$ 1000.00$. It was thought that this expenditure could be further reduced on the basis of observations resulting from a 1-D analysis for the orbital decay case. It is noted that the characteristic ballistic coefficient for the Pioneer $F$ heat source results in the initial half of the orbital decay remaining at rarefied flight conditions and a correspondingly mild thermal environment. Intuitively, this portion of the flight period should have a secondary influence on predicted maximum temperatures for the heat source assembly. It appeared that the thermal response for the heat source during this initial period of flight could be adequately approximated by conducting a steady state analysis using a time weighted cold-wall heating rate rather than examining the complete transient heating rate profile as normally done. The advantage of using a steady state analysis would be to significantly reduce computer cost from the expenditures associated with the explicit transient solution currently available in SHTP. This concept was initially evaluated by an implicit one-dimensional analysis of the heat source using the CMA code. (2) The results are shown in Figure 6 . This figure compares the fuel capsule's clad temperature response based on the transient heating rate profile from initial entry to impact (Curve 2) to the temperature response based on a time weighted steady state heating rate applied over the initial 1390 seconds (i.e., $\left.\int_{0}^{1390} \dot{q} d t / 1390\right)$. The use of a steady state heating rate in the CMA still represents a transient solution 
which will approach a steady state solution as a limit. This can be observed by the shape of Curve 1 which is approaching an asymptote, namely, the steady state solution. Although substantial differences are noted within the first 1400 seconds, it is important to note that the critical parameters of interest, peak temperature and impact temperature, are within $1.5 \%$ of each other (based on changes from the initial temperature). This difference would have been less had the heating rates been averaged over the free molecular heating regime (approximately 0 to 1000 seconds) since the rapid change in heating rates beyond this time point tends to bias the averaging process. This brief exercise indicates a steady-state analysis, with its attendant cost savings, has potential for estimating the temperature response of a heat source in the free molecular heating regime of an orbital decay reentry. Unfortunately, there was insufficient time to pursue this concept in further depth for the Pioneer $F$ program, particularly in terms of the two-dimensional heat source model. Further studies will be conducted in this area in the future.

For the Pioneer F studies, the orbital decay analysis was segmented into two transient solutions wherein the free molecular heating regime $(0-1000$ seconds) utilized the Revision 4 heat shield model shown in Figure 5 and the remaining flight period utilized the recommended Revision 2 model. The Revision 4 mode 1 should result in only a slight excursion in temperature predictions since the transient thermal environment during this period is "slow and low". The cost for an orbital decay analysis utilizing the Revision 2 heat shield mode1 throughout the flight period was estimated to be $\$ 1030.00$. The use of the Revision 4 model during the free molecular heating regime 
reduced this expenditure to $\$ 670.00$. A steady state solution with reasonable convergence characteristics should further reduce the computer expenditures for an orbital decay analysis. This Section and Section $\mathrm{V}$ demonstrate the cost savings potential to be realized through model optimization, particularly when long period reentries (e.g., orbital decay) constitute a major portion of a safety analysis. As an addendum to the above discussion relating to Figure 6 , it is emphasized that the temperature profiles in this figure be viewed on a comparative basis rather than in terms of predicted magnitudes per se. A one-dimensional analysis will overpredict the thermal response of the internal heat source structure during the reentry heat pulse due to neglect of circumferential conduction relief effects occurring from the windward to the cooler leeward stations. This becomes evident by comparing these results to the clad member temperatures presented in Figure 7 for the two-dimensional orbital decay analysis. 


\section{DISCUSSION OF RESULTS}

Temperature distributions for the heat source were determined for two superorbital reentries at initial conditions of $\gamma=-8^{\circ}, V=$ 40,000 fps $\left(-8^{\circ} / 40 \mathrm{~K}\right)$ and $\gamma=-6^{\circ}, V=37,000$ fps $\left(-6^{\circ} / 37 \mathrm{~K}\right)$, and also for an orbital decay. The $-6^{\circ} / 37 \mathrm{~K}$ reentry represents a condition near the multiple skip reentry boundary and can yield large integrated heat loads (i.e., moderate heating rates for prolonged flight periods). The $-6^{\circ} / 37 \mathrm{~K}$ trajectory was not investigated by Teledyne; wherein, the other trajectories, $-8 \% / 40 \mathrm{~K}$ and orbital decay, were investigated by Teledyne and the present analysis can be directly compared to Teledyne results. The $-8 \% / 40 \mathrm{~K}$ reentry was selected by Teledyne as representative of superorbital trajectories for which maximum flight temperatures may be expected. This case was utilized in Teledyne's variational and error analysis to establish a thermal failure $V-\gamma$ space. The orbital decay was investigated because of the relatively high probability of having a launch abort which produced such a trajectory and because the orbital decay yields maximum impact temperatures.

The critical thermal design parameters for the heat source are the fuel capsule's clad member maximum temperature and strength member impact temperature. The $\mathrm{Pt} / 20 \% \mathrm{Rh}$ clad alloy has a nominal melt temperature of $3860^{\circ} \mathrm{R}$. However, the Teledyne safety analysis used a failure criterion of $3460^{\circ} \mathrm{R}$ for clad melt, predicated on the fact that the platinum rhodium alloy can form a low melting eutectic with either T-111 alloy (the strength member) and/or graphite. The experimentally determined range of temperatures in which the platinum rhodium alloy reacts significantly with these materials has been quoted at about $3560^{\circ} \mathrm{R} \pm 50$. (16) 
The impact failure criterion for the strength member is nominally based upon a maximum allowable temperature at impact of $2860^{\circ} \mathrm{R}$, which was the test temperature for granite impact tests $(17)$ and drop tests. The granite impact tests indicated that the strength member breached via ductile failure at shallow impact angles. (The impact angle is the angle subtended by the fuel capsule's longitudinal axis and the target surface.) Although the tests were by no means conclusive, the limited data suggest the use of a $2860^{\circ} \mathrm{F}$ maximum allowable impact temperature. For given impact conditions such as velocity, angle of incidence, target material, etc., the establishment of a failure criterion should be based on an evaluation of the countering effects, as the temperature is increased, of increasing ductility versus decreasing strength for a load-carrying refractory. This type of an evaluation could not be conducted for the Pioneer program because the maximum impact test temperature was restricted by facility heater limitations.

Temperature histories for several members of the heat source assembly are presented in Figures 7,8 and 9 for the orbital decay, $-8 \% / 40 \mathrm{~K}$ and $-6 \% / 37 \mathrm{~K}$ reentries respectively. These temperature histories represent the thermal response of the forward windward positions and are identified by nodal numbers via Figure 3 . Only the temperature data for the second half of the orbital decay flight period have been presented.

Table 2 compares the clad member's maximum flight temperature and strength member's impact temperature predicted by the Teledyne and APL analysis. The Teledyne temperatures for the orbital decay and $-8^{\circ} / 40 \mathrm{~K}$ reentries results from direct analysis whereas the $-6^{\circ} / 37 \mathrm{~K}$ results have 
been obtained from Teledyne's isotherm plots in $V-\gamma$ space that were presented in the SNAP 19/Pioneer F SAR. (10) The peak clad isotherms in the more severe region of $V-\gamma$ space are indicated in Figure 10. Table 2 indicates the APL results to be consistently higher for both maximum flight and impact conditions. The effects contributing to these differences are felt to be principally (a) differences in heat shield modelling and (b) Teledyne's omission of subsonic oxidation effects. A comparison of the APL and Teledyne heat shields at the windward face is shown in Figure 11. Both the Teledyne and APL mode1s possess a three node radial grid. However, the APL model defines the radial temperature gradient by four temperature points, as opposed to Teledyne's three, since the heat shield's external surface temperature is determined directly from the surface energy balance. Consequently, Teledyne's radial distribution is more coarse and should result in lower internal temperatures during the reentry heat pulse as was observed in the optimization studies discussed in Section $V$. It also appears that the Teledyne model may possess greater circumferential conduction effects at the stagnation region (nodal array 191, 181, 171) by including separated flow heating effects in the adjacent nodal array (i.e., array 110 and $192,182,172$ ). Unfortunately, there was insufficient circumferential temperature distribution data in the SAR to substantiate the effect. The absence of subsonic oxidation in the Teledyne analysis is due to the over specification of an oxidation cut-off temperature in their oxidation mode1. This effect is discussed in detail in the Pioneer F/SNAP 19 heat source ablation studies. (18) Lower impact temperatures will result from the Teledyne analysis since 
exothermic heating due to graphite oxidation will be omitted in the heat shield's surface energy balance during subsonic flight. The large temperature difference observed for the clad for the $-6^{\circ} / 37 \mathrm{~K}$ reentry in Table 2 appears as an anomaly vis-a-vis the results for the other reentries. This anomaly is believed due to an erroneous description of peak clad isotherms in proximity of the multiple skip reentry boundary. This is indicated by Teledyne's calculation of $2862^{\circ} \mathrm{F}$ for the $-5.5^{\circ} / 35 \mathrm{~K}$ reentry shown in Figure 10 (i.e., a value that disagrees with the location of the $2800^{\circ} \mathrm{F}$ isotherm sketched by Teledyne.) Consequently, the temperature in parenthesis in Table 2 has been obtained by re-fairing the isotherms and is probably more representative for the $-6^{\circ} / 35 \mathrm{~K}$ case. This adjusted value is also more in keeping with the other reentry results.

The differences shown in Table 2 don't appear to significantly alter the impact fuel release probabilities reported by Teledyne. The principal effect of APL's higher temperature predictions is to slightly enlarge the V-Y space for clad melt failure. This can be illustrated in Figure 10. Teledyne's nominal analyses has indicated the clad melt failure space to encompass the multiple skip region and a slight portion of the prompt reentry space as defined by the $3000^{\circ} \mathrm{F}$ isotherm. Again, it could be argued that the Teledyne isotherms are stated on the low side in proximity of the skip boundary (i.e., the $2800^{\circ} \mathrm{F}$ isotherm is more like $2900^{\circ} \mathrm{F}, 3000^{\circ} \mathrm{F}$ isotherm more like $3050^{\circ} \mathrm{F}$ ) which, if adjusted, would further increase the prompt reentry failure space. The limited data from APL's analysis suggest the clad failure space is slightly more extensive in the prompt reentry region as 
approximated by the cross-hatched region in this figure. It is noted that a portion of this prompt $V-\gamma$ space (which includes the Teledyne failure space) has previously been identified as a heat shield ablation failure zone yielding atmospheric fuel release. (18) The resulting $V-\gamma$ space forward of Boundary $B$ roughly approximates the clad melt failure space yielding post impact fuel release. This space suggests a low occurrence probability and did not justify further analyses to substantiate the boundary. It requires mentioning that the preceding predictive comparisons and discussion are based on nominally conditioned analyses. The effect of APL's slightly higher predicted clad temperatures on Teledyne's error analyses could not be readily assessed. Intuitively, the effect should be sma11, particularly if the clad melt criterion is relaxed to a higher value (e.g., $\left.3560^{\circ} \mathrm{R}\right)$. The limited APL results indicate the orbital decay reentry yields the greatest strength member impact temperature as was observed in Teledyne's extended analyses. Both the Teledyne and APL results exceed the $2860^{\circ} \mathrm{R}$ impact criteria as defined earlier in this section. The results of Table 2 were reported at the final Pioneer $F$ nuclear safety review meeting • 


\section{THERMAL MODEL REFINEMENTS}

In anticipation of future applications for the SNAP 19 RTG, the heat source thermal model is subject to refinement in the following areas :

(a) Heat Shield Recession: APL's current version of the Standard Heat Transfer Program (SHTP) does not account for node dropping within the thermal network as a result of heat shield ablation. A shrinking heat shield geometry will affect heat transfer conduction to the interior structure and intuitively should slightly increase peak clad temperatures and reduce impact temperatures from the levels predicted in the Pioneer $F$ analysis. A node dropping scheme represents a priority item in APL's current plans for computer program development. It is of interest to note that Teledyne assessed the effects of heat shield recession in their Pioneer $F$ analysis and showed little change in peak clad or impact temperatures from the results obtained for a fixed heat shield geometry. A similar result has been observed in Ref. (4) for a simplified heat shield model run on a $-9 \% / 44 \mathrm{~K}$ trajectory. The differences between the fixed and receding surface were shown to be negligible. These results are encouraging but require validation in future studies.

(b) Heat Transfer and Flow Field Distributions: The hexagonal external configuration of the heat source dictates that heat transfer and flow field distributions as a function of surface distance be obtained experimenta11y. The Pioneer $\mathrm{F}$ analysis is based solely upon hypersonic heat transfer distribution data obtained experimentally at a fixed Reynolds number. It is important that this data base be extended as a function of Reynolds number in the hypersonic regime for 
future safety analyses. Furthermore, distribution data should also be obtained in the supersonic regime both as a function of Mach number and Reynolds number. These data will greatly improve the quality of the analyses, particularly with regard to the possibility of transitional and turbulent boundary layer heating occurring at the windward face. Experimenta1 pressure distributions are a further data requirement necessary in improving the analyses. These data will permit a more accurate definition of the surrounding flow field's enthalpy distribution as well as local pressure effects on graphite ablation predictions.

(c) Gap Heat Transfer: The calculation of gaseous conduction heat transfer rates across internal gaps can be refined by (a) evaluating gaseous conductivity as a function of both pressure and temperature (i.e., effects of a rarefied pressure condition) and (b) considering a variable gap size as determined by the instantaneous temperatures of the adjacent structural members. Current practice is to maintain a fixed gap dimension throughout reentry (an averaged value) and evaluate gaseous conductivity as a function of temperature at a fixed pressure level. 


\section{CONCLUSIONS}

Within the curent framework of the APL thermal model, heat source temperature predictions for various check point reentries generally validate the thermal results reported by Teledyne-Isotopes in their Pioneer $F$ reentry safety analysis. Specifically, the APL temperature results for peak clad and strength member impact conditions are slightly higher than Teledyne's values and suggest a slightly larger $\mathrm{V}-\gamma$ space for the clad melt failure zone. However, the additional $V-\gamma$ failure zone suggests a negligible increase in the fuel release probabilities reported by Teledyne for ground impact conditions. This comparison is based on nominal type analyses as opposed to error analyses used by Teledyne Isotopes in determining final failure probabilities. 
1. Barber, L.A., et. al., A Guide to the Usage of the Standard Heat Transfer Program (PL/I), BCP-441 Revision 1, August 1969.

2. Users Manual, Aerotherm Charring Material Thermal Response and Ablation Program, Version 3 -Volumes I, II, Report UM-70-14, Aerotherm Corporation, Mountain View, California, April 1970.

3. Users Manual, Aerotherm Equilibrium The mochemistry Computer Program, Version 3 - Volumes I, II, Report UM-70-13, Aerotherm Corporation, Mountain View, California, April 1970.

4. Frazer, R.K., Conn, D.W., "Development of a Surface Energy Balance Routine for Non-Charring Ablation Analysis", (To be published)。

5. SNAP 19/Pioneer F Safety Analys is Report - Volume I, INSD-2873-42-2, Teledyne-Isotopes, Timonium, Md., June 1971.

6. Nicke1, H.S., Plasma Arc Reentry Simulation Test Report, SNAP 19 Pioneer Heat Source Safety Program, INSD-2873-79, Teledyne-Isotopes, Timonium, Md., July 30, 1971.

7. Hagan, J.C., The Effect of Mass Asymmetries on the Reentry Motion of the Pioneer Heat Source, BBA-3-71-023 (ANSP-005), Applied Physics Laboratory, Silver Spring, Md., Oct. 28, 1971.

8. Conn, D.W., Comparative Review of Teledyne-Isotopes and Sandia Laboratories Pioneer F Safety Reentry Therma1 Analyses, ANSP-003, Applied Physics Laboratory, Silver Spring, Md., August 1971.

9. Schumann, F., Evaluation of Gaps Between Heat Source Components During Reentry, INSD-FAS-9649, Teledyne-Isotopes, Timonium, Md., Dec. 4, 1970。

10. SNAP 19/Pioneer F Safety Analysis Report - Volume II, INSD-2873-42-2, Teledyne-Isotopes, Timonium, Md., June 1971. 
11. Detra, R.W., et. al., Addendum to 'Heat Transfer to Satellite Vehicles Re-entering the Atmosphere", Jet Propulsion, Vo1. 27, December 1957, pp. $1256-1257$.

12. Sibulkin, M., Heat Transfer Near the Forward Stagnation Point of a Body of Revolution, Journal of Aeronautical Sciences, Vol. 19, No. 8 , August 1952 .

13. SNAP 19 Pioneer Heat Source Hypersonic Heat Transfer Test Report, INSD-2873-80, Teledyne-Isotopes, Timonium, Md., July 30, 1971.

14. Callis, L.B., Solutions of Blunt-Body Stagnation Region Flows with Non-gray Emission and Absorption of Radiation by A Time Asymptotic Technique, NASA TR R-299, Lang ley Research Center, Hampton, Va.

15. Perini, L.L., Review of Graphite Ablation Theory and Experimenta1 Data, ANSP-M-1, Applied Physics Laboratory, Silver Spring, Md., December 1971.

16. Blumentha1, J.L., Orgen, J.R., LASL Twx to R. Len Topper, AEC Headquarters, dated Apri1 26, 1971.

17. SNAP 19 Pioneer Heat Source Safety Program, Granite Impact Test Report, INSD-2873-77, Teledyne-Isotopes, Timonium, Md ., July 23, 1971.

18. Conn, D.W., Pioneer F/SNAP 19 Heat Source Ablation Studies, ANSP-M-2, Applied Physics Laboratory, Silver Spring, Md., February 1972. 
Tab le 1

Effect of Variations in Heat Shield Modelling on

Predicted Fue 1 Capsule Clad Member Tempe ratures and

Computational Costs

\begin{tabular}{|c|c|c|c|c|c|}
\hline $\begin{array}{l}\text { Heat Shield } \\
\text { Mode } 1\end{array}$ & ${ }_{\mathrm{clad}}^{\mathrm{T}} \underset{\mathrm{o}}{\mathrm{o}} 55 \mathrm{sec}$ & $\mathrm{T}_{\mathrm{clad}}{ }_{\mathrm{o}}, \max$ & $\begin{array}{l}\text { Flight Time } \\
\text { sec }\end{array}$ & ${ }^{*}$ Computer Time & $\begin{array}{l}* * \text { Computer Cost } \\
\text { Flight Time, } \$ / \mathrm{sec}\end{array}$ \\
\hline Baseline & 2337 & $* k * k_{3241}$ (est) & 55 & 861.5 & 3.92 \\
\hline Revision 1 & 2343 & & 60 & 492.2 & 2.05 \\
\hline Revision 2 & 2308 & 3191 & $\begin{array}{l}274.5 \\
\text { (impact) }\end{array}$ & 463.5 & .43 \\
\hline Revision 3 & 2243 & 3128 & 220 & 500.6 & .57 \\
\hline
\end{tabular}

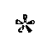

Does not include time for compilation and link editing phases which are equivalent for all phases.

$* *$

Cost rated at $\$ .25$ per computer second (approx.).

$* * * *$

A conservative estimate based on earlier comparisons ( $<55 \mathrm{sec}$ ) between Baseline and Revision 2 cases. Baseline and Revision 1 cases prematurely termminated due to excessive computer time expenditure.

*w*** This evaluation was conducted for a $-9^{\circ} / 44 \mathrm{~K}$ fps reentry condition at 400,000 feet. 
Table 2

Comparison of Two-Dimensional Thermal Results

for the

Pioneer F SNAP 19 Heat Source

Entry

(1) Orbital Decay from $400,000 \mathrm{ft}$.
Temperature Parameter

a) Peak, Clad Member

b) Impact, Strength Member
Temperatures, ${ }^{\circ} \mathrm{R}$ APL

3380

3070

3165

b) Impact, Strength Member 2541

at $400,000 \mathrm{ft}$. a) Peak, Clad Member

Impact, Strength Member
$T-I$

3287

2933

3055

2463
Temperature

Difference

93

137

(3) $\gamma=-6^{\circ}, V=37,000$ fps

a) Peak, Clad Member

3443

$3260^{*}(3360) 183(\sim 85)$

at $400,000 \mathrm{ft}$.

b) Impact, Strength Member

2650

65

* An adjusted value based on a reconsideration of T-I's peak clad isotherms in proximity of the multiple skip boundary in $V-\gamma$ space. 
THE JOHNS HOPKINS UNIVERSITY

APPLIED PHYSICS LABORATORY

SILVER SPRING MARYLAND

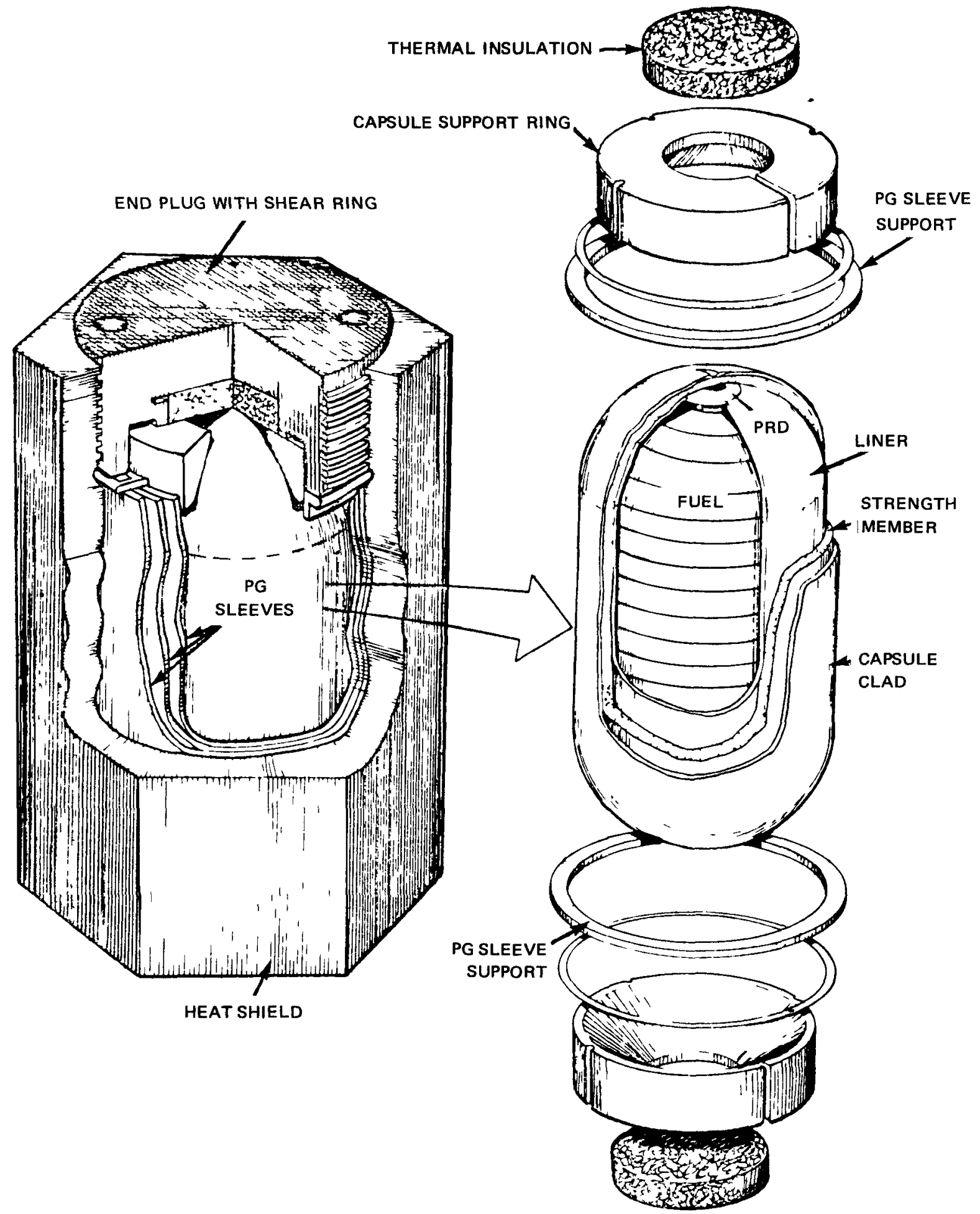

FIg. 1 PIONEER F/SNAP 19 HEAT SOURCE DESIGN 


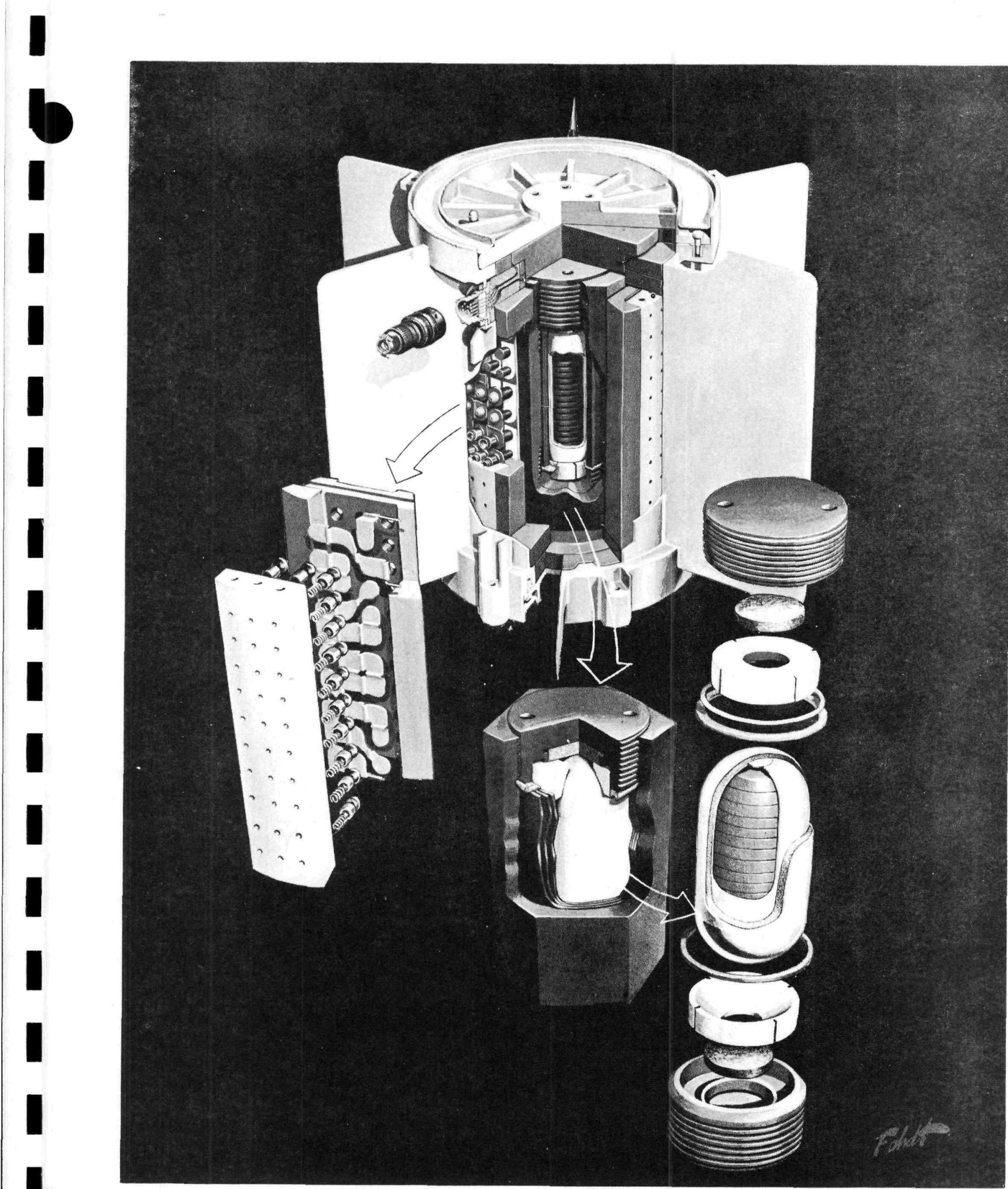

Fig. 2 THE SNAP 19 PIONEER F RADIOISOTOPE THERMOELECTRIC GENERATOR WITH T-111 FUEL CAPSULE 


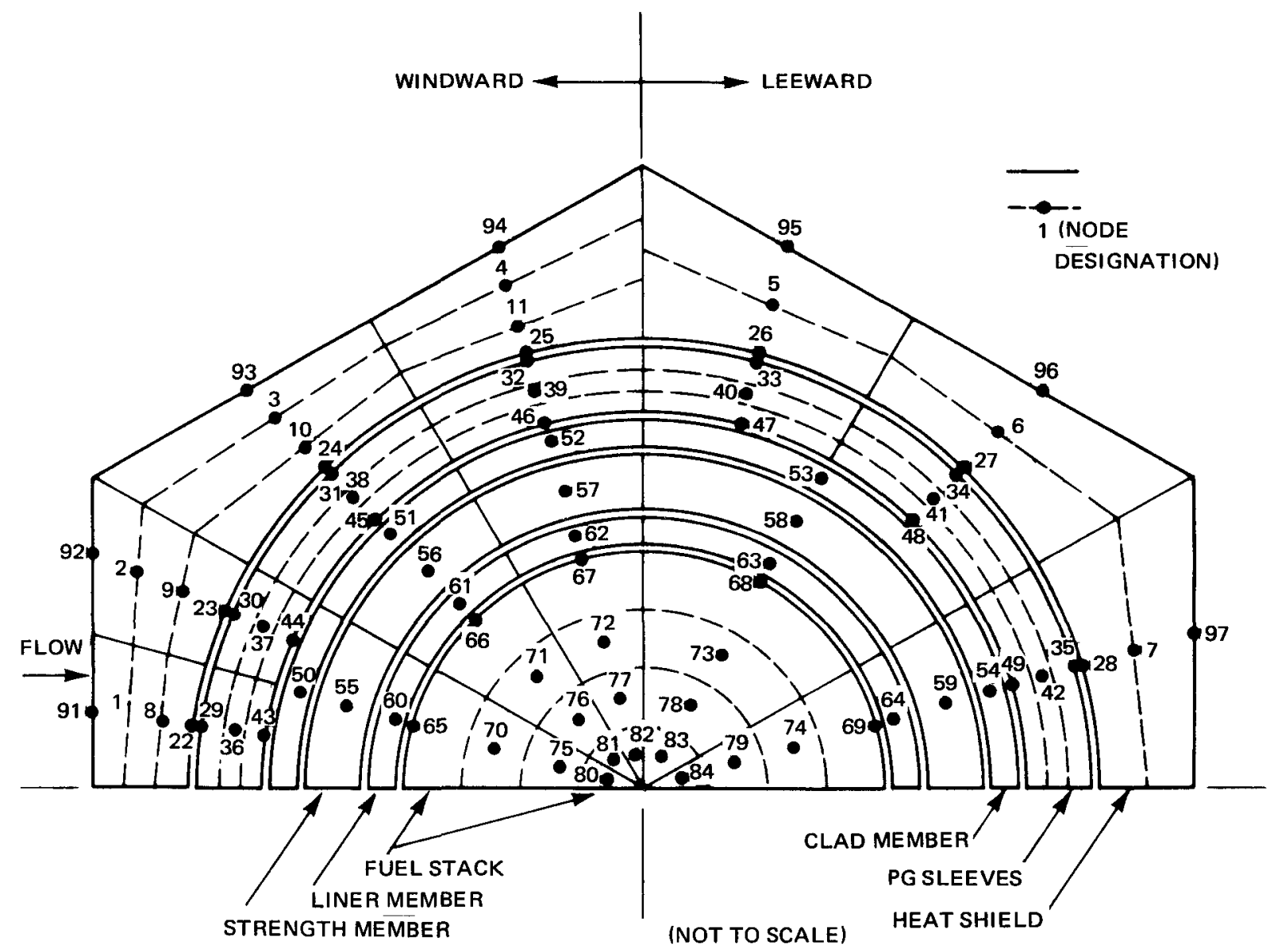

Fig. 3 PIONEER F/SNAP 19 HEAT SOURCE TWO DIMENSIONAL THERMAL MODEL 


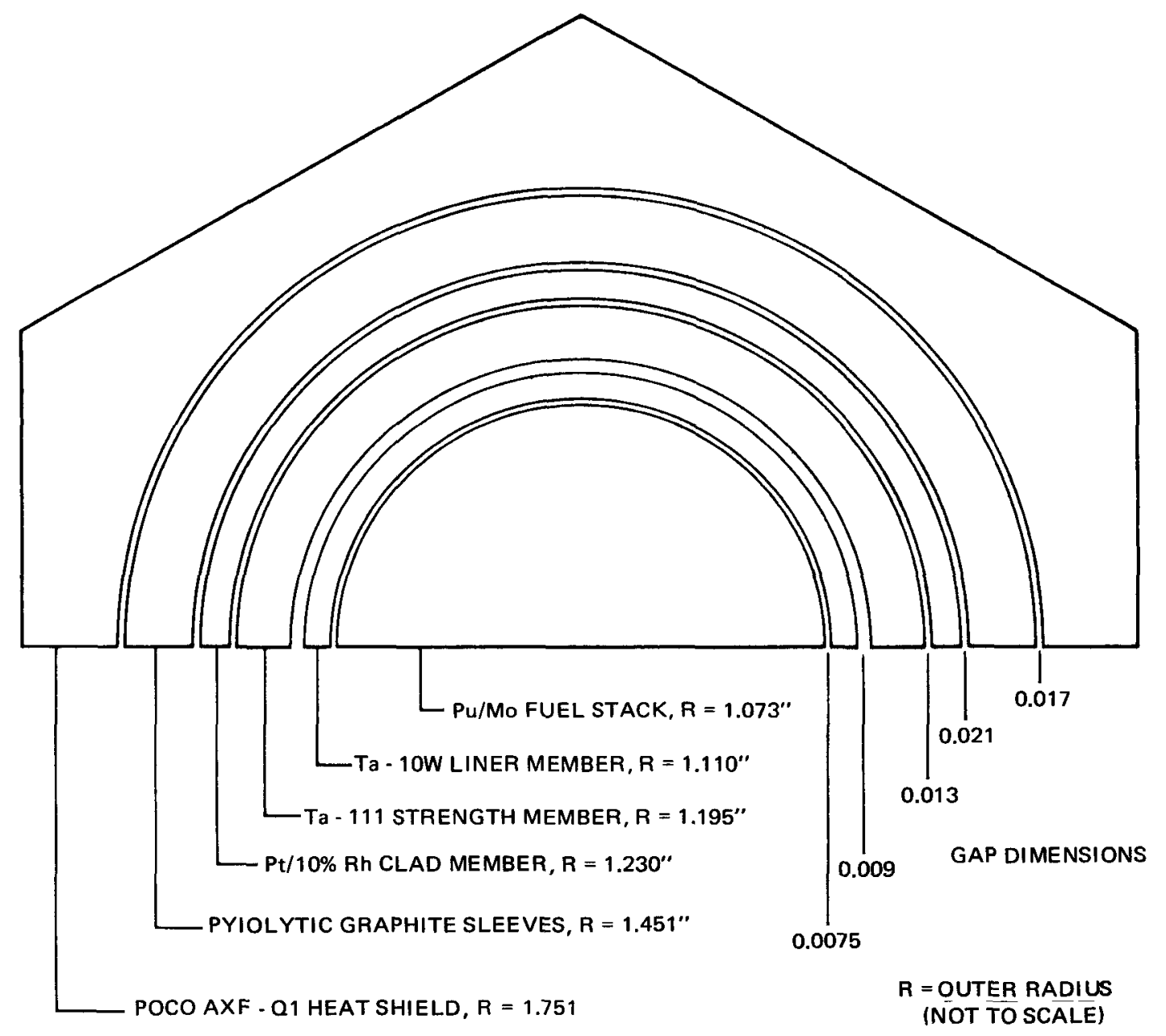

Fig. 4 PIONEER F/SNAP 19 HEAT SOURCE DIMENSIONS AND GAP DISTRIBUTION 


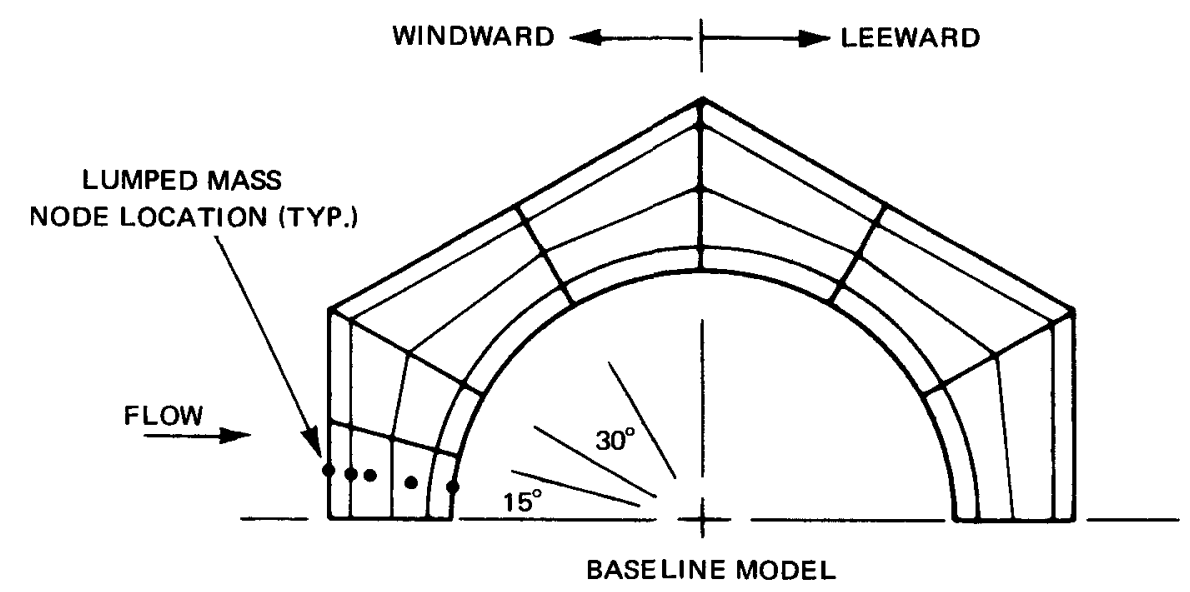

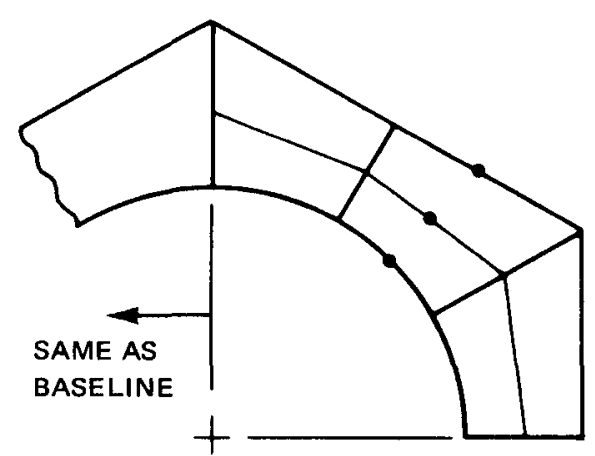

REVISION 1 MODEL

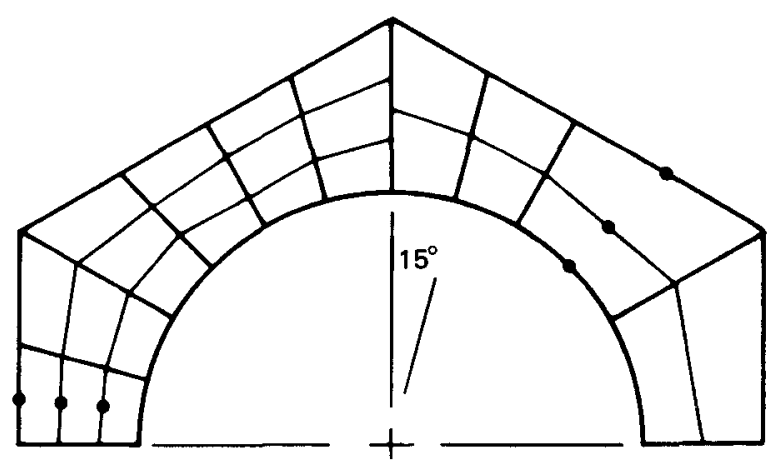

REVISION 3 MODEL
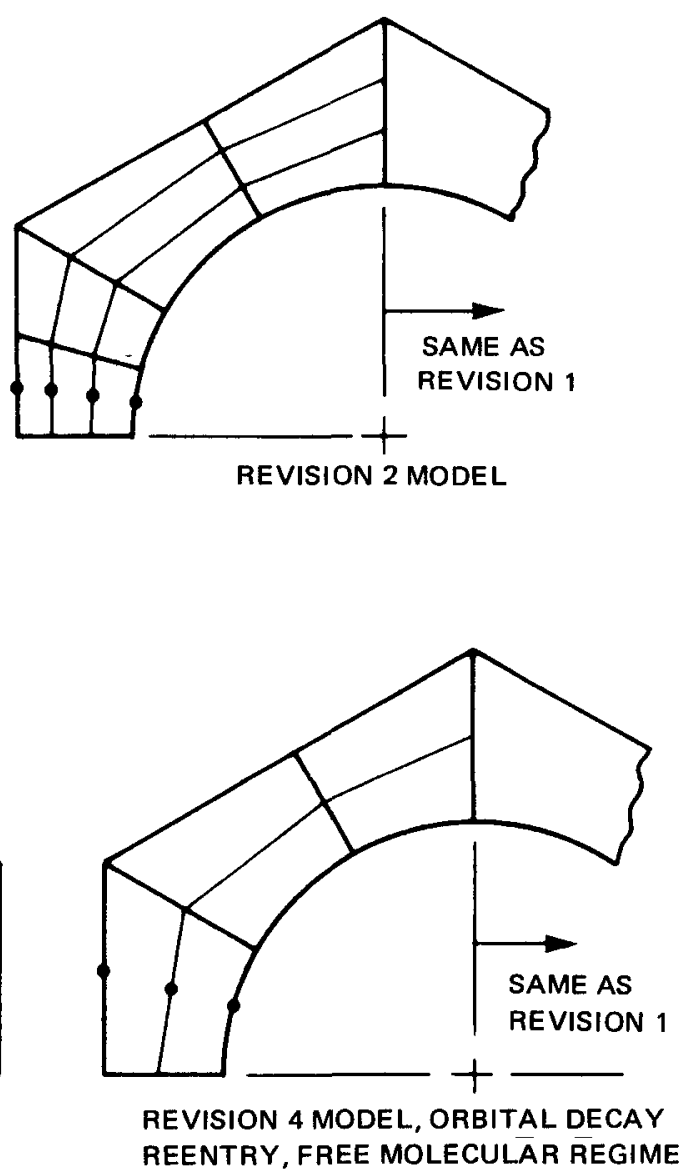

Fig. 5 HEAT SHIELD THERMAL MODEL VARIATIONS, PIONEER F/SNAP 19 HEAT SOURCE 
THE JOHNS HOPKINS UNIVERSITY

APPLIED PHYSICS LABORATORY

SiLver SPRING MARYLAND

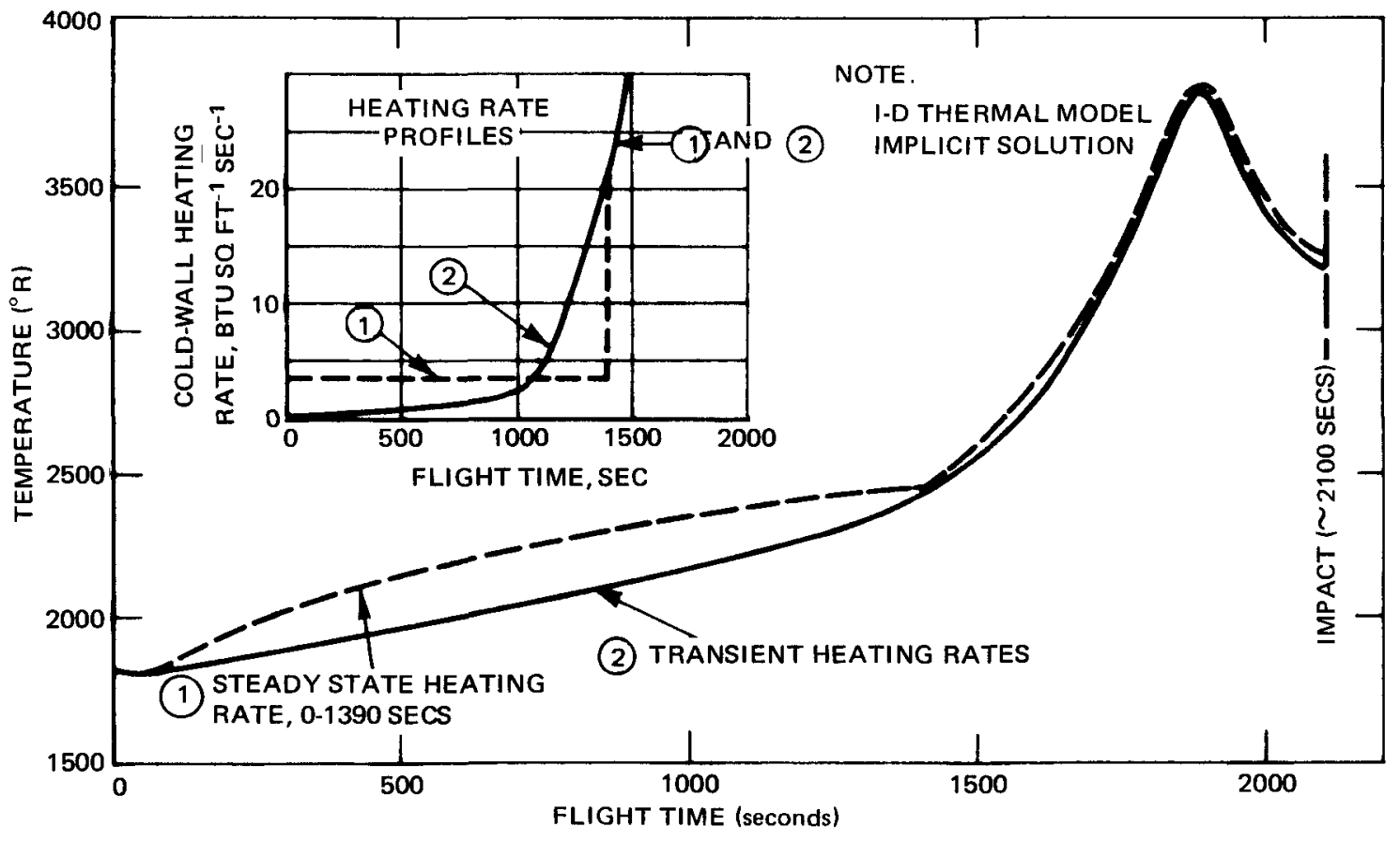

Fig. 6 COMPARISON OF CLAD MEMBER TEMPERATURE PROFILES DUE TO TRANSIENT AND STEADY STATE HEATING RATE CONSIDERATIONS FOR AN ORBITAL DECAY REENTRY 
THE JOHNS HOPKINS UNIVERSITY

APPLIED PHYSICS LABORATORY

SILVER SPAING MARYLAND

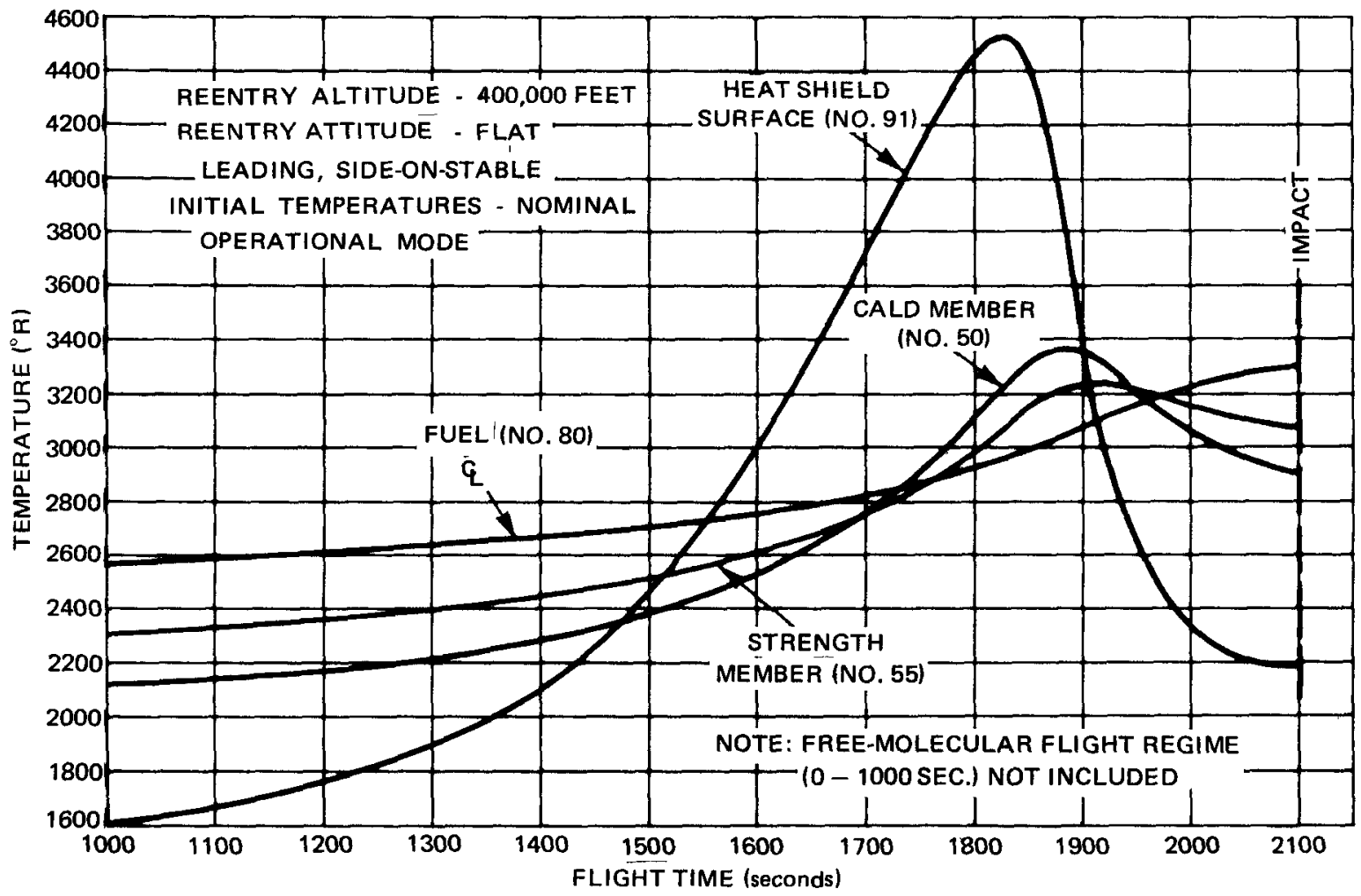

Fig. 7 TEMPERATURE HISTORIES FOR PIONEER F/SNAP 19 HEAT SOURCE FOR ORBITAL DECAY REENTRY 
THE JOHNS HOPKINS UNIVERSITY APPLIED PHYSICS LABORATORY Silver SPRING. MaRrLAND

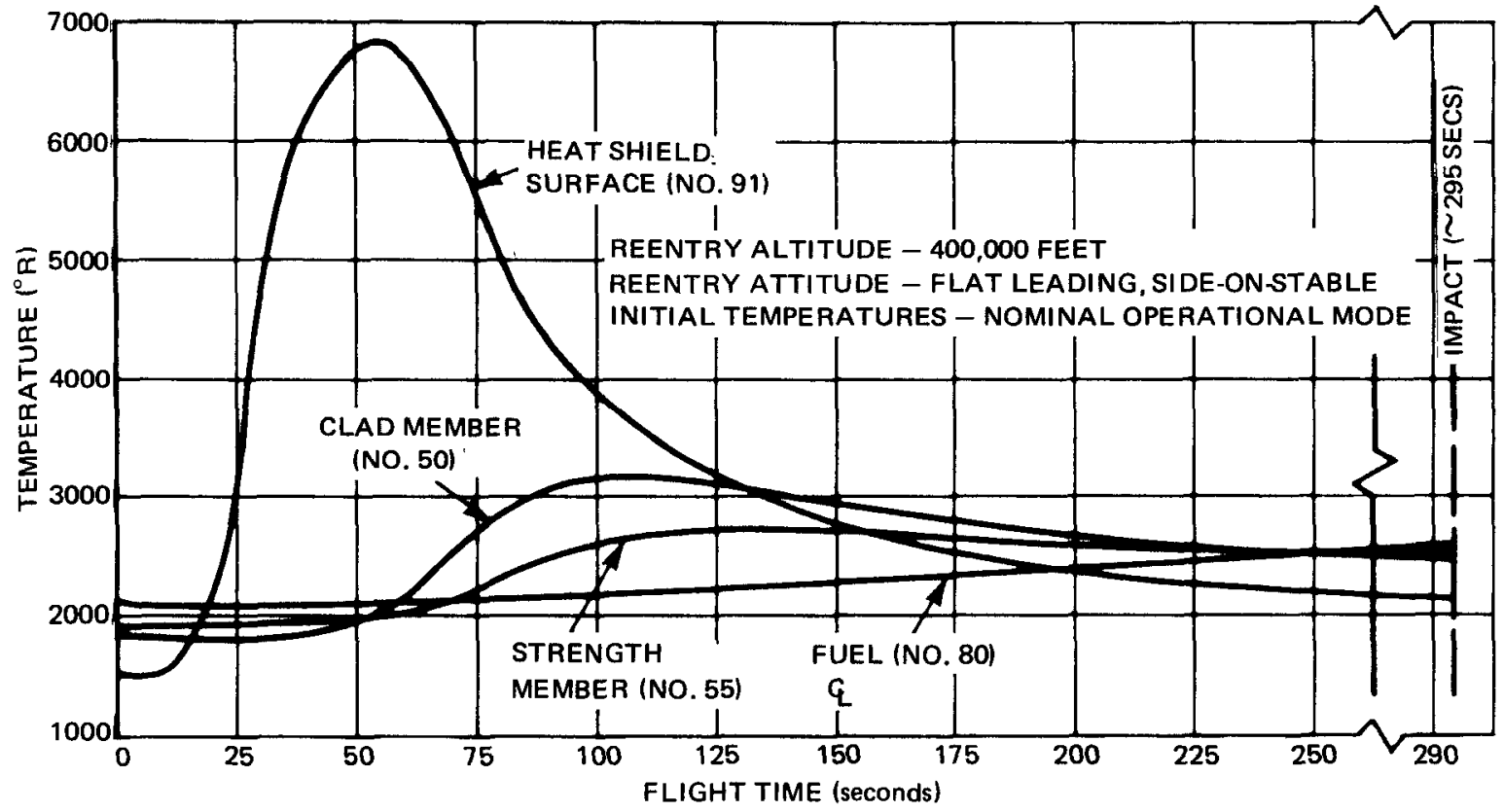

Fig. 8 TEMPERATURE HISTORIES FOR PIONEER F/SNAP 19 HEAT SOURCE FOR $\gamma_{i}=-8^{\circ}, V_{i}=40000$ FPS REENTRY 
THE JOHNS HOPKINS UNIVERSITY APPLIED PHYSICS LABORATORY

SILVER SPRING MARYLAND

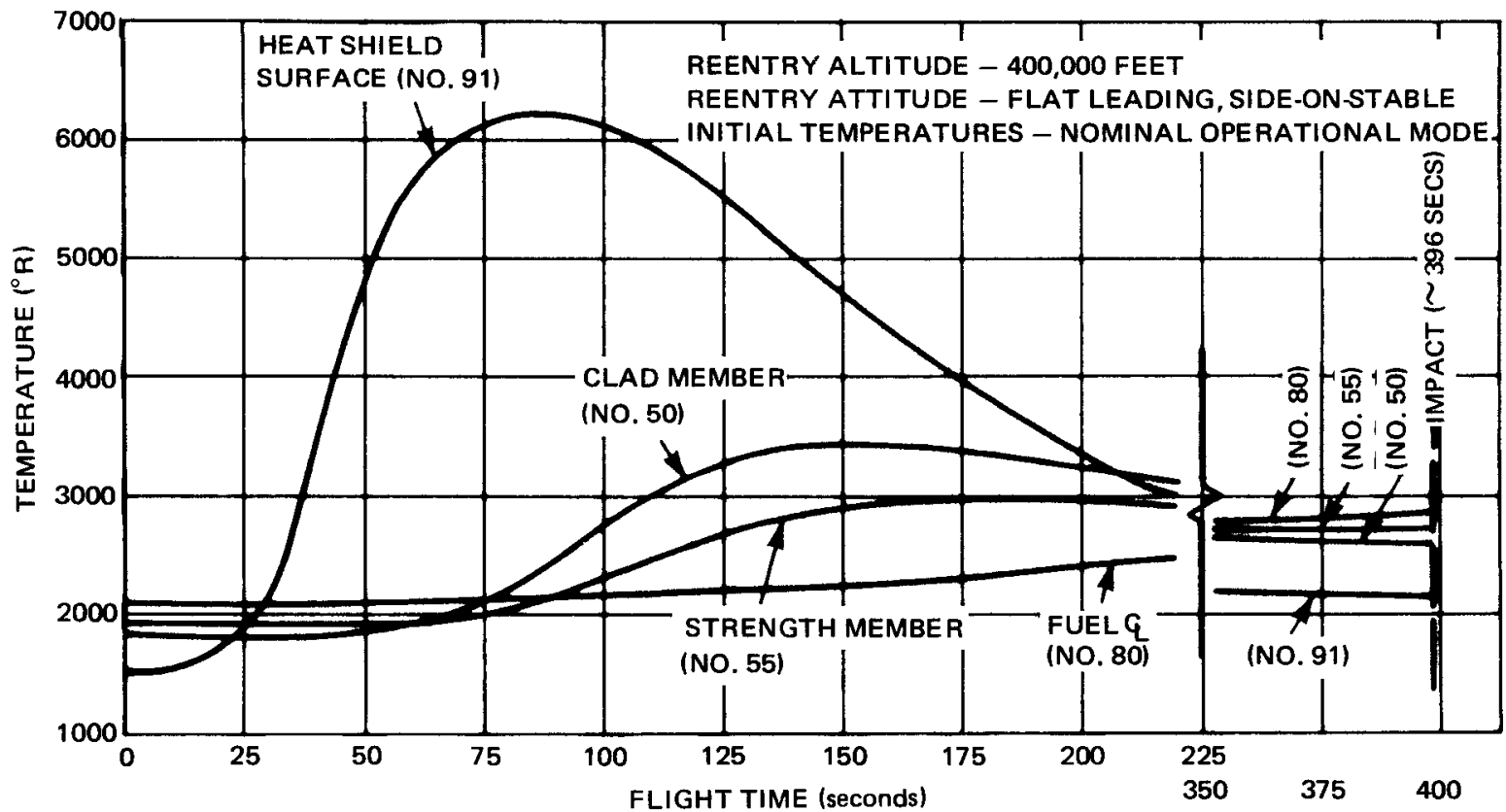

Fig. 9 TEMPERATURE HISTORIES FOR PIONEER F/SNAP 19 HEAT SOURCE FOR $\gamma_{i}=-6^{\circ}, v_{i}=37000$ FPS REENTRY 


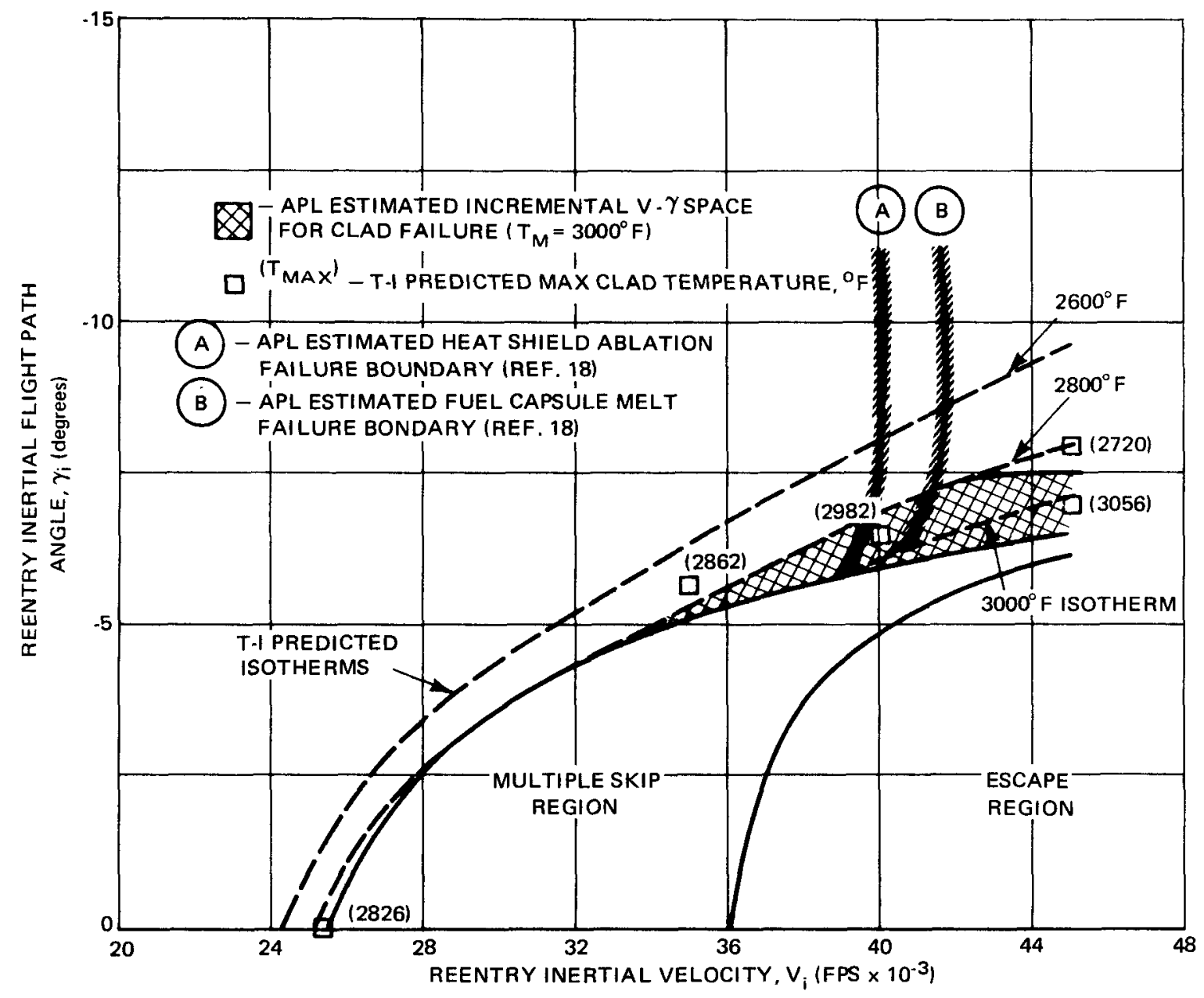

Fig. 10 APL ESTIMATION OF INCREMENTAL V- $\gamma$ SPACE FOR CLAD MELT FAILURE 


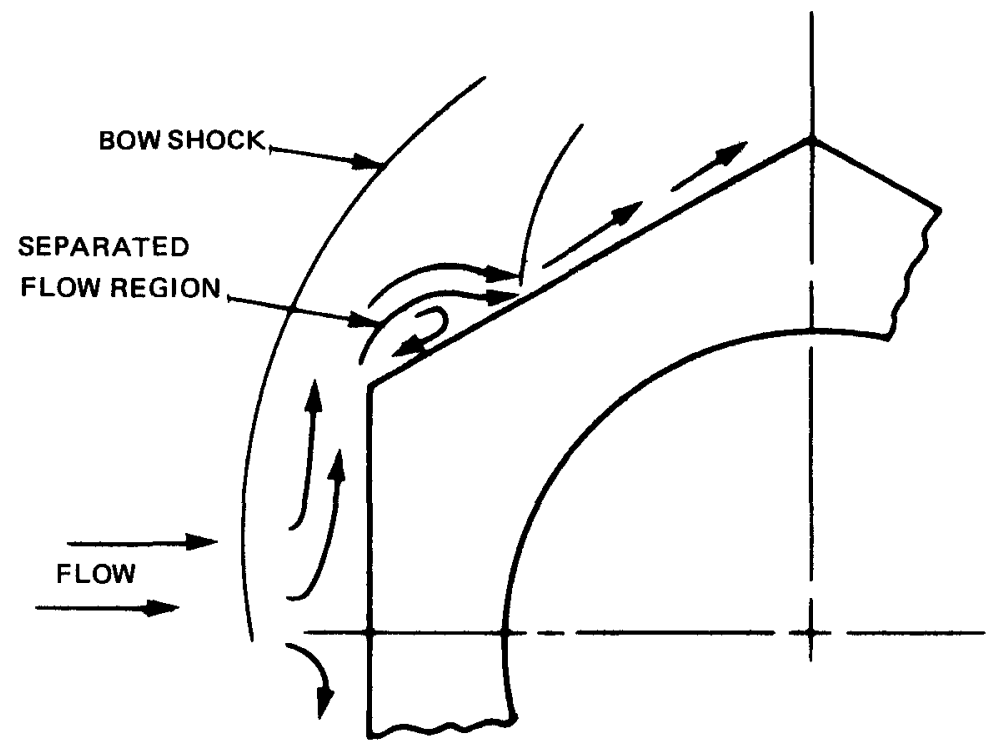

(a) FLOW FIELD OVER WINDWARD FACE OF HEAT SHIELD

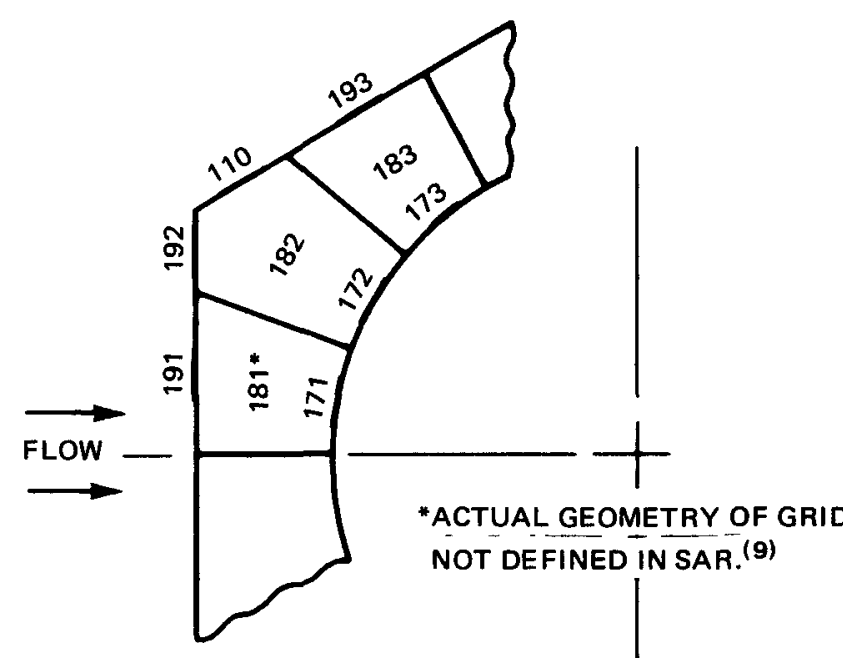

(b) T-I HEAT SHIELD MODEL, FORWARD WINDWARD LOCATION

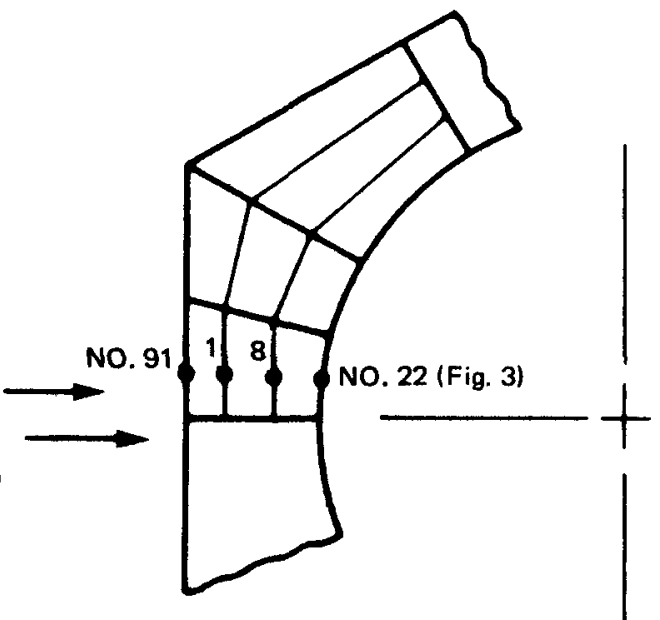

(c) APL HEAT SHIELD MODEL, FORWARD WINDWARD LOCATION

Fig. 11 COMPARISON OF T-I AND APL HEAT SHIELD THERMAL MODELS, PIONEER F/SNAP 19 HEAT SOURCE 